\title{
2
}

\section{Scanning and Sensemaking}

Despite the important role of organizational processes and behavior (OB) to this book, we have to come clean from the start with a basic truth: Even good OB won't save bad strategy. The links between the two are so strong that the converse is true: A great strategy is likely to be undone and proves unsustainable by terrible $\mathrm{OB}$. We will leave aside for the moment many of the detailed implications of this connection-not least that $\mathrm{OB}$ comes in more flavors than "vanilla" and organizational design decisions need to take into account the nature of the strategy.

Yet, one useful starting point that might sound like a Zen koan or riddle is that every competitive undertaking requires a good "starting point," a good strategic direction and that a poor strategy may not survive even in a vibrant, growing industry. This was far from obvious not so long ago-there is a long tradition of Industrial Organization $(\mathrm{I} / \mathrm{O})$ Economics research that pointed to significant differences in performance and profits purely because of the structure of the industry (e.g., level of competition or concentration, barriers to entry, etc.), never mind the quality of the managers. But the view today is much more balanced-we recognize the importance of business-level conditions, and this includes the quality of the strategy. You could have the finest managers available on the market, and an amazing market full of growth opportunities, and still fail. For example, trying to compete with better handset mobile devices — as Nokia did — when the key category of distinction became superior software and platform thinking was going to lead to disappointment, and this despite the fact that the smartphone industry in the mid-2000s was set for an amazing, out-of-this-world growth 
period. Failure also came despite the ability to hire the "best of the best" managers, as Nokia almost certainly could in the run-up to the smartphone boom. ${ }^{1}$ So, while this relationship is not unidirectional and a great strategy can unravel with bad OB, let's start with the premise that there are better and worse strategies, and that this makes a big difference to performanceit's not just the industry and not just the quality of daily management.

\section{What Is "Good" Strategy, Really?}

Fortunately a former colleague Richard Rumelt has spent a good deal of time discerning good from bad strategy. ${ }^{2}$ At the risk of oversimplifying, Rumelt says that bad strategy amounts to impressive statements of ambitions and goals, but little else. It's what happens when strategy is reduced to financial or market objectives and packaged mainly for external consumption - "our strategy is to be the market leader and most trusted brand for our customers, to deliver superior products, excellence, and outstanding value, to grow to new heights and produce sustained shareholder value. Simply put, our strategy is to be Number 1 in the core markets that we serve." Although exaggerated, some version of this strategy statement is probably familiar to you, a superlative-laden but no less generic and vacuous strategy script that could apply to many settings. We could take a step further and give this statement some flavoring — and strategies for a long time have come not in one but two flavors, chocolate ("we will offer the best quality and technical performance") and vanilla ("we will offer the lowest price"). But even with these flavorings, these statements tell us little about the real strategy.

What is a good strategy then? Once again, at the risk of oversimplifying the thoughtful work of Rumelt, I will focus on one aspect in particular. A good strategy has a generous articulation of the context, of the perception of value in the market segment being targeted and the scope of games that can be played in order to deliver that value. Bad strategy statements, on other hand, are ones which are ultimately of little conceptual worth, and this is mostly because they are relatively context-less. They provide no good read on the sources of value and the nature of advantage.

\footnotetext{
${ }^{1}$ Vuori, T. O. and Q. N. Huy. (2015). "Distributed Attention and Shared Emotions in the Innovation Process: How Nokia Lost the Smartphone Battle." Administrative Science Quarterly 61(1): 9-51 (p. 29 footnote).

${ }^{2}$ Rumelt, R. P. (2011). Good Strategy Bad Strategy. New York, Random House.
} 
Let's look more closely at what Rumelt calls the kernel of a good strategy, which he boils down to three main elements ${ }^{3}$ :

- "A diagnosis that defines or explains the nature of the challenge. A good diagnosis simplifies the often overwhelming complexity of reality by identifying certain aspects of the situation as critical.

- A guiding policy for dealing with the challenge. This is an overall approach chosen to cope with or overcome the obstacles identified in the diagnosis.

- A set of coherent actions that are designed to carry out the guiding policy. These are steps that are coordinated with one another to work together in accomplishing the guiding policy."

These form the "kernel," because they are the central players in the construct we call strategy-there are other parts (mission, vision, scope, objectives, etc.), but ultimately these rely upon the presence of an energy source, the thoughts and arguments that lay bare the actual value and advantage to be had. Rumelt used the example of 3-D graphics chipmaker Nvidia as a company that went from laggard in 1995 to market leader a dozen years later by embracing each of these key elements of good strategy. Nvidia's simple diagnosis was "We are losing the performance race," so the CEO JenHsun Huang's guiding policy for dealing with this situation was to "release a faster, better, chip three times faster than the industry norm." The coherent actions Nvidia took to bring the guiding policy to fruition included forming three chip development teams with overlapping schedules and investing in huge, efficient facilities fabricating chips and software drivers. Nvidia overtook competitors Intel and 3Dfx to be named "Company of the Year" by Forbes in $2007 .{ }^{4}$

Think of a sci-fi film in which these giant intergalactic spaceships and stations are ultimately fueled by some tiny, glowing precious object in the center of the ship. Like these sci-fi radiating energy sources, we have the kernel of a strategy-they pretty-much fuel the rest. In the above definition from Rumelt, the italics are in the original, but I have underlined portions to highlight the kernel within the kernel, namely a deep read and appreciation of context. This context includes the "aspects of the situation," which create the potential for value creation, the methodology or "overall

\footnotetext{
${ }^{3}$ Ibid. (Chapter 5: TITLE AND PAGE \#s).

${ }^{4}$ Rumelt, Richard. (2011). “The Perils of Bad Strategy.” McKinsey Quarterly 1(3): 1-10, June. Retrieved August 19, 2019. https:/www.mckinsey.com/business-functions/strategy-and-corporate-finance/ our-insights/the-perils-of-bad-strategy.
} 
approach" that must specifically tackle those "obstacles identified," which we sometimes call customer pain points, and, ultimately, the "coordinated" actions that must work together to deliver and capture the recognized value. Doing this involves looking outside the organization, but it includes making the connection to the inside, to the possible actions an organization can connect and carry out from bringing core processes, such as this first one, scanning and sensemaking, to bear.

Today more and more leaders are starting with a careful, critical, and creative read of the strategic context, but they are not necessarily leaders of incumbent firms. The leaders who "get" context are more likely to be associated with what we colloquially call "disruption," in the form of new companies, or companies not traditionally associated with an industry. Disruptors sense something different in that industry, a new potential for value creation. Consider two examples, both in old-school, well-established industries, one in entertainment services, and the other in automobile manufacturing.

Netflix invents Binge-watching - Netflix is a massive video entertainment company, and yet it owns no conventional movie-making or distribution infrastructure (e.g., cinemas). It recognized earlier than most not only that technology would soon be available to comfortably stream large video files to people's homes, but, perhaps more importantly, CEO Reed Hastings and Chief Content Officer Ted Sarandos identified an inefficiency when lining up programming and considering short self-contained sit-coms vs. hour long dramas with seasons' long story arcs. For the latter they realized viewers found linear TV watching annoying-patiently waiting during the week for a favorite TV show or film to be broadcast and then hoping to get to the TV in time to watch, then sitting through a dozen or more minutes (for a one hour show) of commercials, most of them seeming to have little to do with you. And in fact this realization has a lot to do with one of the tenets outlined in the by-now famous Netflix "Culture deck," created by Hastings and Chief Talent Officer Patty McCord, that stipulates Context vs. Control, particularly apt for the scanning and sensing backstage leader. McCord says that learning how to "set context" for people is one of the most effective leadership traits.

The more you see yourself as a teacher rather than a teller or permission-giver, the more effective your team will be. The idea of context is really, really important. Who are our competitors? Where are we at? ...What feedback are we 
getting from our customers? Who are they? How do we stay in touch with them? How do we send out involvement? Just constantly keeping people informed. ${ }^{5}$

Netflix employees sensed that the confluence of technology and consumer behavior was ripe for a new way to access our favorite programming by having it available to stream all at once. Its algorithms also help viewers discover other, related content they may enjoy, including new content they are now developing. In this way, the company recognized consumers' new appetite for "binge-watching" TV series that they may have missed the first time around. For instance, Netflix realized that becoming the streaming syndicator for the once big-hit Mad Men and past seasons of similar shows solved the inefficiency of TV watching and was a boon to consumers who wanted to "catch-up" in a hurry. Binge-watching took off; during peak times, Netflix can account for about $1 / 3$ rd of all Internet traffic. ${ }^{6}$

Tesla Model 3 Overtakes Luxury Rivals-Tesla still manages to be the darling of the automotive world, despite production and delivery setbacks with most of their models. That it still captures so much attention and goodwill is a testament to the strength of its vision and insight into our love affair with "cars"- not transportation, not things green, but cars. Deliciously designed, heart-poundingly accelerated, cars. Early founders Martin Eberhard and Marc Tarpenning were "looking for a problem," as Marc Tarpenning described it when speaking to one of my executive classes. The problem was our world's over-reliance on fossil fuels and the negative environmental and political spillovers this created. Their painstaking research and reasoning eventually brought them to the realization that lithium-battery power was moving in the right direction, at the right speed, and would be a viable source of energy for cars, providing impressive "well-towheel" efficiency compared to not only fossil fuels but also other rising alternatives, such as ethanol, fuel cells. Plus car manufacturing had developed into a staggering ecosystem - there is very little of the various parts that go into a car that could not be purchased through this global supply chain.

\footnotetext{
${ }^{5}$ Kruse, Kevin. (2018). "Netflix Culture Deck Co-Creator Says Leaders Need to Explain Context." Forbes, February 19. Retrieved August 21, 2019. https://www.forbes.com/sites/kevinkruse/2018/02/19/ Netflix-culture-deck-co-creator-says-leaders-need-to-explain-context/\#bb3528b590c2.

'Nocera, J. (2015). "Can Netflix Survive in the New World It Created?" The New York Times Magazine. New York Times (New York), June 15. Retrieved December 10, 2019. https://www.nytimes. com/2016/06/19/magazine/can-netflix-survive-in-the-new-world-it-created.html.
} 
Beyond the technology, however, they noticed something else. Electric cars, while being offered in 2003, were targeted to technology and environmental enthusiasts, and some of the designs and performance were truly awful. So while many more drivers than just enthusiasts would be interested, or at least curious, in a purely electric vehicle, they were not willing to give up on style and performance. The market was ripe for an electric car that wasn't in a separate category to, say, BMW, Mercedes, Lexus, or Cadillac, but that did the things these cars do using clean, recharge-over-night, gasoline-free technology and with the bonus of a no-haggling, transparent online sales process. Eberhard, Tarpenning, and soon afterward Elon Musk sensed these forces. His strategy, as he says all along, was to enter the market at the high end, at which customers are happy to pay a premium, and then, with each successive model, push for higher unit volume and lower prices. Musk accomplished this strategy with the Model 3 by hiring ever more workers, going through what he called "production hell," and incurring massive losses, but he created what is a historic moment in automotive transportation. Tesla's Model 3 , the company's first car midsized car and its first targeted at middle- and upper-class families with a price tag of $\$ 35,000$, outsold luxury competitors in 2018, including BMW, Mercedes, Audi, Lexus, Alfa Romeo, and Jaguar. The electric car industry is, however, still in its infancy and there have also been some storms for Tesla of late-the next part of their story is far from clear, and the entire industry is being challenged, but we should at least expect Tesla to continue to reach toward disruptive ideas (big improvements in autonomous driving, Internet of things connectivity within the vehicle, etc.). ${ }^{7}$

Netflix and Tesla are just two of the companies that have managed to scan and sense new opportunities in the environment. Here are others that have been heralded for throwing out the gossamer strands of their scanning spider webs and capturing previously unexploited opportunities:

Airbnb - the other iconic story in disruption is this leading accommodation provider (without the real estate) that saw that many of our properties are underutilized resources and that with the rise of the sharing economy, we would be willing to rent from each other.

Rent the Runway - also capitalizing on the dwindling lack of cache in ownership, Rent the Runway bet that consumers would rather not shell out

\footnotetext{
${ }^{7}$ Baer, D. (2014). "The Making of Tesla: Invention, Betrayal, and the Birth of the Roadster." Business Insider, November 11. Retrieved December 10, 2019. https://www.businessinsider.fr/us/tesla-the-origin-story-2014-10; Dans, Enrique. (2018). "Tesla, The Model 3...And the Market." Forbes, August 4. Retrieved December 10, 2019. https://www.forbes.com/sites/enriquedans/2018/08/04/ Tesla-the-model-3-and-the-market/\#1cc6906577ed.
} 
$\$ 1200$ to own a Christian Siriano dress but rent one for $\$ 150$, make a fab impression, and send the dress back in a prepaid envelope three days later. The Harvard grad founders have since expanded to curated capsule collections from 39 brands - why not rent your wardrobe?-and home goods as well.

WhatsApp — now owned by Facebook, this international messaging app found opportunity in tapping mobile data channels, instead of expensive SMS, for peer-to-peer messaging, and with easy onboarding, security, and no advertising.

Duolingo - once the standard of achievement for mastering English as a Foreign language the TOEFL test has been disrupted by Duolingo, a language learning app that offers online instruction in 30 languages for free, including English, and the replacement of the costly \$250 TOEFL test with one that costs only $\$ 49$ and has won acceptance by top universities and institutions. ${ }^{8}$

BlaBlaCar - while ride-sharing companies like Uber and Lyft have garnered attention, French long-distance ride-sharing company BlaBlaCar scanned its environment long before them to solve the "empty seat problem," for Europeans commuting long distances, often between different European cities. In 2003, three co-founders launched a platform that would allow cash-strapped young people to share rides securely. Unlike with Uber and Lyft, BlaBlaCar drivers don't make a profit and are discouraged from doing so; they recoup their costs, nothing more, while BlaBlaCar takes an $11 \%$ cut of amounts paid, and BlaBlaCar passengers pay $79 \%$ less than a rail ticket for the same trip. In 2018, it had over 50 million users. ${ }^{9}$

Who knows where these companies eventually end up? Exogenous shocks will emerge, presenting new challenges-like the Coronavirus, which may create greater uncertainty around the "sharing" economy. Yet, what is undeniable is that they have developed strategies because of some penetrating insights into the context - the markets, technologies, and consumer behavior around them.

\footnotetext{
${ }^{8}$ CNBC. (2019). "Meet the 2019 Disruptor 50 Companies." May 15. Retrieved August 19, 2019. https://www.cnbc.com/2019/05/15/meet-the-2019-cnbc-disruptor-50-companies.html.

${ }^{9}$ Gannes, Liz. (2013). "Europe's BlaBlaCar Has Created the Purest Version of the Sharing Economy So Far-And It's Working-All Things D." The Wall Street Journal, December 2. Retrieved December 10, 2019. https://techcrunch.com/2018/09/24/BlaBlaCar-is-on-the-path-to-profitability/; More on BlaBlaCar: Brewis, Kathy. (2017). "Harnessing the Winds of Change: BlaBlaCar." London Business School, July 17. Retrieved December 10, 2019. https://www.london.edu/lbsr/ iie-harnessing-the-winds-of-change-BlaBlaCar.
} 


\section{Dynamic Capabilities and Scanning}

To recap, I have argued so far that (a) good versus bad strategies are more important than we may acknowledge to performance, (b) the "kernel within the kernel" of a good strategy is seeing novel sources of value within a strategic arena, and (c) the leading disruptive companies of our times seem to have done this well. The rest of the chapter will examine what this means for incumbent companies, and for incumbent managers, who have daily duties that capture their attention and energy. After all, established managers simply do not have the time to work in a purely free-wheeling, entrepreneurial fashion, yet, all the same, they face the key issue of tracking storms and finding the next opportunity. Let's look at some foundations in management theory and research to this scanning work.

There has been a lot of ink and pixels spent on the topic of "dynamic capabilities" in strategy and organizational academic circles in the past two decades. The search term produces over two million hits in Google, about three times more than "cheap flights to vegas" and roughly the same order of magnitude as "The Big Lebowski." David Teece defined the concept in 1997 as, "the firm's ability to integrate, build, and reconfigure internal and external competencies to address rapidly changing environments." 10 The basic idea of dynamic capabilities is simply to "do stuff that creates new competitive advantage," but the devil is in the details, as we will see.

Organizations are full of routines - repetitive sequences of thought and action that get work done within organizations. You know these well and use them every time your company holds a committee meeting, fulfills a purchase order, hires an employee, merges two departments, and so on. For our purposes, there are three things to note about routines. First is that they are the cornerstone of productivity because they are fundamentally about specialization. By definition, they are things that we do repetitively and so, normally, we should gain proficiency through repetition. The first time a manager holds a brainstorming session incorporating design-based thinking or agile teams, for example, may feel awkward and clunky, but by the 100 th time it should feel more natural, work faster, and basically be more efficient. Second, they involve groups of individuals. The most interesting routines are ones that connect various pieces of lower-order work-not less important work, but work that forms a building block for larger processes.

\footnotetext{
${ }^{10}$ Teece, David, Gary Pisano and Amy Shuen. (1997). "Dynamic Capabilities and Strategic Management." Strategic Management Journal 18(7): 509-533.
} 
Product development is a good example of a very large "meta" routine that is made up of many smaller routines; they're modular. Finally, routines can also involve "not-so-routine" work, such as change, innovation, discovery, exploration, and so on. So, we can distinguish ordinary routines, which tend to have higher frequency and more to do with maintaining, or incrementally improving, the way things work, from higher order routines. ${ }^{11}$

Dynamic capabilities are about these higher order, innovation-oriented, transformative, and future-proofing routines that happen less frequently and are fundamentally about substantial dynamism and change. The irony, and the fascination, of dynamic capabilities is that firms can have enduring, repetitive, systematic routines for the express purpose of generating something with value that will inevitably have an expiry date, is a unique outcome (i.e., a once-off creative path), and requires big doses of creativity. That successful, innovative firms have these "dynamic capabilities" is generally an accepted fact by now, and so when we consider what is probably the poster child for a resilient, re-inventive organization-Appleit is safe, and easy, for academics and journalists to assume that Apple has some enduring, repetitive, systematic behaviors and thinking which allows it to disrupt and not be disrupted. But the problem has always been to define these dynamic capabilities more precisely, to move from abstract, "they-must-be-there-because-we-can-see-their-shadows" thinking to actually articulating the building blocks of these routines. It is, in many ways, the search for the fountain of youth within strategy and organizational research. After all, what business leader would not want to attend a course or read a book on "Everything you wanted to know about keeping your company relevant and successful forever!"? The good news is that coherence has been accumulating as to what dynamic capabilities actually look like, and the most coherent yet concise description I can offer is that dynamic capabilities have a lot to do with recombinant thinking, that is the capacity to reuse existing resources but in novel ways, to meet new and emerging needs in the marketplace. ${ }^{12}$ In fact product development engineers and researchers Jacob Goldenberg and Rom Y. Schrift studied past product launches in multiple

\footnotetext{
${ }^{11}$ Teece, D. J. (2007). "Explicating Dynamic Capabilities: The Nature and Microfoundations of (Sustainable) Enterprise Performance." Strategic Management Journal 28(13): 1319-1350; Teece, D. J. (2012). "Dynamic Capabilities: Routines Versus Entrepreneurial Action." Journal of Management Studies 49(8): 1395-1401.

${ }^{12}$ See Galunic, D. C. and S. Rodan. (1998). "Resource Recombinations in the Firm: Knowledge Structures and the Potential for Schumpeterian Innovation." Strategic Management Journal 19(12): 1193-1201; Galunic, D. C. and K. M. Eisenhardt. (2001). "Architectural Innovation and Modular Corporate Forms." Academy of Management Journal 44(6): 1229-1249.
} 
industries to reveal that $70 \%$ of successful innovations followed one of five distinct patterns and less than $20 \%$ of failures contain them. They advise thinking "inside the box," rather than outside; these patterns or templates spring from looking closely at components and attributes of existing products to come up with new ones. For example, by multiplying components of an existing product, in this case Gillette's disposable razor, the company created the Trac II razor in 1971, showing how one blade lifts the hair, while the second blade cuts it. They multiplied existing components again in 1998 to create the Trac III, the world's first triple-blade razor. This time the first blade lifted, the second cut, and the third cut even closer, giving the company a reputation for giving consumers the "closest shave."13

There has been some good conceptual work done on describing the practical foundations of dynamic capabilities, ${ }^{14}$ but I don't think we will ever be able to refine dynamic capabilities into a simple recipe. There will always be the need for managerial discretion and judgment, but also wading through a diverse set of underlying routines and thinking, in other words a good deal of complexity. There is also the inherent tension between dynamic capabilities_-doing the right things — and ordinary routines, which are about doing things right. These activities are in enough opposition that the job of making the company successful in the short-run acts as a brake on making the company successful in the long run, but maintaining that balancing act is inherent to successful backstage leadership work, a key theme for our chapter on managing contradictions (Chapter 4 ) and one that we will return to.

\section{Spinning Your Spider's Web}

One of the bedrocks of dynamic capabilities is the capacity for scanning. In most models of dynamic capabilities, it is the starting point. Scanning is the equivalent of a spider's web-multiple vectors of inquiry (listening and engaging) that capture strong but also weak signals in the environment about the future. The key issue is the ability to sense weak signals, the signals that are not obvious and that others are likely to miss. Spiders, with notoriously poor vision, don't rely on sight but on sound and vibration frequencies to

\footnotetext{
${ }^{13}$ Goldenberg, Jacob. and Rom Y. Schrift. (2018). "Go Forth and Multiply: Unlocking Successful Innovation." Columbia CaseWorks Case: 190501.

${ }^{14}$ Eisenhardt, K. M. and J. A. Martin. (2000). "Dynamic Capabilities: What Are They?" Strategic Management Journal 21: 1105-1121; Teece, D., M. Peteraf and S. Leih. (2016). "Dynamic Capabilities and Organizational Agility: Risk, Uncertainty, and Strategy in the Innovation Economy." California Management Review 58(4): 13-35.
} 
detect movement changes as fine as $1 / 1000$ th the width of a human hair. ${ }^{15}$ Presumably, there is very little that happens within a spider's web that the spider would not detect. Scanning requires, then, managers to craft search maps and ongoing routines for enquiry and the detection of possible novelties (threats and opportunities). You will not be performing classic "R\&D" work because scanning tends to involve cultural and behavioral trends and is rather more inductive rather than deductive. It clearly has something to do with what we defined as the "kernel of the kernel" of good strategy, which is the ability to unpack and understand your strategic arena. Where to begin, then? Here are some basic scanning steps managers can take from the backstage:

1. When you develop a comprehensive search map, you should cut a wide swath and include many categories, such as:

- Science institutions (universities, labs);

- Customers (from extreme to average users, in shops or on social media);

- Competitors;

- Trade associations and conferences;

- Analogous organizations/substitutes (i.e., noncustomers);

- Suppliers;

- Regulators;

- Demographics;

- Political and public policy changes.

2. Make a judgment call on the frequency of engagement across the different categories in your search map (yearly, monthly, weekly, daily-because you cannot afford to be in "pure" entrepreneurial mode in all areas at all times) and build a process that duly links these enquiries back to your strategic decision-making.

Good scanning is notoriously difficult and for the same reasons that forecasting and human decision-making are notoriously difficult and prone to failures. This was the case for Nokia, which certainly did scan the environment and would have been at least aware of the software and

\footnotetext{
${ }^{15}$ Arnold, Carrie. (2014). "Spiders Listen to Their Webs." National Geographic, June 5. Retrieved December 10, 2019. https://news.nationalgeographic.com/news/2014/06/140605-spiders-silk-webspluck-string-vibrations/\#close.
} 
platform-thinking storm that was building in Silicon Valley and yet that wasn't enough. ${ }^{16}$ Mastering scanning routines in fact have less to do with the act of scanning per se and more to do with other topics in $\mathrm{OB}$ and its related kin, such as decision sciences and forecasting. The most important topic, too often disconnected from the work of scanning, is the field of sensemaking.

\section{Combining Sensemaking with Scanning to Track Trends and Occurrences}

Let's take a short step back and consider the ultimate question behind this chapter-the sourcing of new strategies. One line of academic thinking that is seldom spoken of in polite executive circles is that, actually, there is very little management choice involved, that leaders are almost completely constrained by the ecological forces surrounding their industries, or as one study summarized this view: "managers matter only as seamless conduits of plans based on matches between organizational capabilities and environmental conditions." 17 This view posits managers are "rubber stamps" with their new market entry decisions completely guided by some powerful matching logic, namely the match between the capabilities of the company and the nature of the threat/opportunity, along with some pretty basic and widespread motivations, such as to foil rivals. This may feel insulting to practitioners, being reduced to a mere clerk caught within evolutionary forces, but it's not so crazy if we think of the vast multitude of strategic decisions that companies have made over their lifetimes—not just the headline-grabbing ones that make it to the press - and so Honda, which has a core competence in engine design, has naturally entered many markets that require combustion engines, everything from small inline 3-cylinder engines for light vehicle duty, to powerful V6 and V8 IndyCar series engines, to engines for motorcycles, all-terrain-vehicles, watercraft and marine vehicles, even a light business jet engine and an engine for lawnmowers. Honda's strategic logic could be seen to be driven by its core (legacy) capabilities. If we take this viewpoint seriously, we have now reduced the entire scanning process to a mere economic matching algorithm, a supply-demand calculation.

\footnotetext{
${ }^{16}$ Vuori, T. O. and Q. N. Huy. (2015). "Distributed Attention and Shared Emotions in the Innovation Process: How Nokia Lost the Smartphone Battle." Administrative Science Quarterly 61(1): 9-51.

${ }^{17}$ Eggers, J. P. and S. Kaplan. (2009). "Cognition and Renewal: Comparing CEO and Organizational Effects on Incumbent Adaptation to Technical Change.” Organization Science 20(2): 461-477.
} 
But considerable research tells us that this way of thinking is simplistic and imprecise. It turns out that how managers "think," how they interpret and make sense of the conditions that they scan, matters a lot to this process of sizing-up their different contexts and making strategic bets. Let's take a famous example from this literature, the case of Polaroid. ${ }^{18}$

Polaroid was synonymous with instant photography and an iconic design, with the photograph emerging from the front of the camera ready to gowith the image developing in front of your eyes over the course of a minute or so, the process was as fascinating and delightful as the image itself. Founder Edwin Land launched his first "Land" camera in 1948 and developed multiple iterations of his camera and film while running the company, until he stepped down in 1981. Polaroid was technologically advanced, with Land earning hundreds of patents and developing strong pillars not only in areas such as optics and electronics, but also in manufacturing, which were brought in-house, allowing Polaroid to become exceptional at assembling precision parts, and distribution; Polaroid understood early-on that mass market retailers, not speciality shops, would extend the reach to consumers, as long as the cameras continued to deliver Apple-like simplicity to users. As one executive said of the Polaroid culture "What we are good at was major inventions. Large-scale, lengthy projects that other firms would hesitate to tackle." ${ }^{19}$ During those golden days, Polaroid enjoyed an average compounded sales growth of $23 \%$ per year.

By the mid-1980s Polaroid's inventiveness tapped a new arena developing in the electronics age and with obvious ties to its core business: digital imaging. True to its strong technological roots and capabilities, Polaroid approached this space with commitment and fascination: The new CEO was dedicated to the cause, they formed a separate group, and they invested tens of millions in capital and an operating budget, they hired new experts in micro-electronic $\mathrm{R} \& \mathrm{D}$ work, and within 10 years Polaroid achieved a patent for a digital camera system with an accompanying printer. The resulting technologically impressive design was such that Polaroid's sensors could achieve over three times the number of pixels of resolution compared to the majority of the competition. Eventually, they provided a marketing, not just technological, emphasis to this emerging unit, and so the unit's leaders could begin to conceive of the digital imaging experiencing in a new way. Polaroid

\footnotetext{
${ }^{18}$ [An excellent research paper on this story] Tripsas, M. and G. Gavetti. (2000). "Capabilities, Cognition, and Inertia: Evidence from Digital Imaging." Strategic Management Journal 21(10/11): 1147.

${ }^{19}$ Ibid., p. 1151.
} 
should have been set-up for an incredible future. Remember, this is about $10-15$ years before the smartphone revolution in the early to mid-2000s, a revolution that included the realization that digital imaging (and storage and sharing, not just printing) was big sources of happiness in consumer electronics, something people would love to see available in any "gadget" that accompanies them through daily lives. It's no wonder one of the big selling features of each successive launch of the iPhone or Samsung Galaxy is the power of the camera and beauty of the images. In fact, who's to say that the gadgets we call today "smartphones" could not have been called "smartcameras?" In that world, the core technologies around imaging, including presenting that image on some sort of smartscreen, are eventually joined by calendars, PDA elements, telephony, and of course messaging. But that world didn't happen, and it has a lot to do with managerial cognition, how the senior leaders at the time made sense of the world around them.

The story of Polaroid's eventual demise goes like this. Senior leaders conceived of a business model for this new technology that emphasized "instant print," meaning that the whole point of digital imaging, while it simplified image taking by having no film in the camera, was that it had to result in instant, high-quality physical images. These, in turn, would result in the sales of photo paper, ink, and similar consumable materials. The money, they believed, would be in the consumables, not in the hardware, what is commonly known as the "razor/blade" business model (sell the razor cheap, make money on the blade). This was a fundamental and strong assumption in Polaroid senior ranks, what one employee called "an ontological truth." 20 It also happened to be wrong, or least missing the real changes underfoot in our digitizing world — we started to care less about physically printing an image if that image was accessible digitally wherever we go. But that logic was at the core of their thinking, influencing how they made sense of the world around them. This emphasis on making real money on the blade, not the razor, also meant that Polaroid did not take several important investment paths that would have been required in a world that eventually emphasized the "razor." They missed the boat on digital technologies for sharing images, low-cost manufacturing, faster new product development cycles, and marketing to this particular emerging world. Polaroid Corporation would eventually unwind its digital imaging research capability, and of course eventually face bankruptcy, and this despite having a truly impressive lead in digital imaging technology, and a popular name brand.

${ }^{20}$ Ibid., p. 1154. 
So sensemaking matters profoundly to the scanning and strategy development process. Even what seem like "no brainer" contextual signals may be conceived of in very different ways and with serious implications for strategic decisions. This was the finding of a large sample, longitudinal study to investigate when and why telecom companies entered the fiber-optics market. ${ }^{21}$ Clearly, prior R\&D into optics would be a plus as would the level of general sales in each company in the build-up to a strategic decision. But despite various controls for what might predict market entry decisions, the "attention" of the CEO mattered significantly. Specifically, CEO's who were relatively more attentive to existing technologies - that is, where there was substantial CEO inertia in thinking on existing methods for delivering communication solutions - were significantly delayed in market entry decisions, and this despite the organization having a build-up in capabilities, as was true in the case of Polaroid. Moreover, CEO's who were more focused on the affected industry, effectively on the value sensibilities of customers, were more likely to push forward with market entry.

This is partly why Corning, a company once known most for its heavy white casserole dishes, became a first mover in fiber-optic cables, the absolutely pure glass cables that transmit light over thousands of miles without the need for any boosting mechanism or without losing any of the information encoded within them. A team of Corning researchers invented the first low-loss optical fiber in 1970. Like Polaroid, Corning invented a radical technology years before the company had any customers for it, but, perhaps unlike Polaroid, Corning developed its technology in wide-ranging partnerships with other companies and labs. Corning was already vertically integrated with Siemens in the 1970s through a joint venture called Siecor, so they were able to seamlessly become the manufacturing arm for fiber-optic cable once it became clear that telecom consumers needed to surpass copper's ability to transmit information over more miles and with less loss. Gino Cattani describes some of the elements that contributed to Corning's unique scanning and sensemaking abilities:

Corning's senior researchers were encouraged to visit research labs and customers, attend conferences and so on. Moreover, one to three senior researchers who were well-known in the scientific community were selected as Corning's $\mathrm{R} \& \mathrm{D}$ ambassadors. This role of 'technology scouts' - somehow akin to that

${ }^{21}$ Eggers, J. P. and S. Kaplan. (2009). "Cognition and Renewal: Comparing CEO and Organizational Effects on Incumbent Adaptation to Technical Change.” Organization Science 20(2): 461-477. 
of gatekeepers...- was intended to facilitate the acquisition and diffusion of critical knowledge, both technical at the market level. This practice permeated Corning's search behaviour and enhanced its ability to develop new technologies internally building on existing core technical competencies. ${ }^{22}$

What's important to note here is the additional and independent predictive power of managerial sensemaking when it comes to figuring out strategy. This effectively boils down to figuring out the wider market and its technological, cultural, or other contexts. Let's look more closely then at sensemaking.

\section{How Sensemaking Has Its Roots in Leadership}

Sensemaking is essentially scanning with mindfulness, that is with deep, reflective thought. ${ }^{23}$ Before getting into the practical details of how to do this from the backstage, it helps to appreciate three points about the sociological and philosophical roots of sensemaking, and what it has to do with leadership.

(1) In many ways, the essential work of business leaders is to conceptualize. Business leaders don't clean the offices, code software, handle heavy machinery, or tackle after sales support questions. What they do is conceptualize - invoke frames, categories, schemas, and many other cultural elements - for the purpose of understanding but also constructing the world around them. This is not so hard to accept once we have already accepted that everything from "money," to "companies," to "nations," to "marriage," to "bank holidays," to "street fashion," to "glam rock," and many more concepts, are all things we humans make up. They only exist because we say they do, because we have used our capacity for thought and communication and cooperation-and other conceptual building blocksto make them real and, more or less, shared mental constructs. The CEO is effectively the Chief Elucidation Officer. This was effectively what Steve Jobs did within Apple in his second stint at the top-as he renamed it just "Apple" from "Apple Computing" and pushed it into the

\footnotetext{
${ }^{22}$ Cattani, Gino. (2008). "Leveraging In-House R\&D Competencies for a New Market: How Corning Pioneered Fibre Optics." International Journal Technology Management 44(1/2): 28-52; [on Fiberoptic cable] Crawford, Susan. (2019). "How Corning Makes Super-Pure Glass for FiberOptic Cable." Wired, January 8. Retrieved August 21, 2019. https://www.wired.com/story/ corning-pure-glass-fiber-optic-cable/.

${ }^{23}$ Weick, K. E. and K. M. Sutcliffe. (2006). "Mindfullness and the Quality of Organizational Attention.” Organization Science 17(4): 514-524.
} 
"consumer electronics and services" space and away from being just a "computer maker." Of course, reconceptualizing does not always pan-out. This is what The We Company co-founder Adam Neumann tried to do with the co-working company that has expanded to include co-living dorms and private K-8 schools that emphasize entrepreneurship. When he and co-founder Miguel McKelvey founded what was then called WeWork in 2010, they essentially were leasing real estate, chopping it into co-working spaces for entrepreneurs and freelancers to rent. Neumann billed the company as a "community" and a force for bringing people together to change the world. WeWork attracted members (they never call them "tenants") by instituting attractive, hip design, creating intentionally narrow hallways and offices that forced co-workers to interact in shared office spaces, providing free-flowing craft beers, kombucha and hosting pop-up events geared to entrepreneurs. The company was able to raise billions in venture capital from funders who valued it as a virtual community, a tech company. ${ }^{24}$ However, the conceptualizations outstripped reality and the company has floundered badly. ${ }^{25}$ Reality ultimately needs to factor into our wild imaginations. Conceptualization requires imagination and intuition, but also a grounding in reality.

(2) The work of conceptualization is very different from the mere fact of holding or reaching conceptions. The stuff of conceptualizing is alertness, perception, playfulness, abstraction, elevated awareness, and perhaps most of all a tolerance for living always with some amount of confusion. ${ }^{26}$ This is not easy to do for the simple reason that we crave certainties. We like to simplify life and fast. We only have to consider the power of stereotypes-our proclivity to quickly place people or things into demographic boxes or categories-our confirmation biases- the way we interpret and recall information in a way that confirms what we already believe, rather than question it. For example, my colleagues in the decision sciences like to play a little game in class. Students are shown a number sequence, say "3-6-9" and are asked to guess what is the underlying rule for the sequence, which is hidden from them. The students can only guess the rule once, but they can offer as many numbers next in the series as they like, say "12," to which the professor responds with either "fits the rule" or "does not fit the rule."

\footnotetext{
${ }^{24}$ Ulaga, Wolfgang, Joerg Niessing, and Nancy Brandwein. (2019). "WeWork-Service Excellence Through Business Model Innovation: Creating Outstanding Customer Experiences by Leveraging Data, Analytics and Digital Technologies." INSEAD Case: \#TK.

${ }^{25}$ https:/www.theguardian.com/business/2019/dec/20/why-wework-went-wrong (The Guardian Online, Mathew Zeitlin, December 20 2019).

${ }^{26}$ Weick, K. E. and K. M. Sutcliffe. (2006). "Mindfullness and the Quality of Organizational Attention." Organization Science 17(4): 514-524 (p. 515).
} 
That is, they can test what they believe the reality to be and based on those tests, and when they are confident of having discovered the rule, they can try to generalize and solve the puzzle, but only once. So what typically happens? A student will say "12," and my colleague will answer "fits the rule." Then they will try "15," and once again my colleague will say "fits the rule." Now, it doesn't take long for them to try a solution: "the rule is to add 3 to the previous number." To which my colleague says "wrong" with some amount of smugness. Eventually, someone will try a slightly different path. They may start with numbers such as 12 and 15, but may then try 16 and 37, to which the professor will also say "fits the rule." More importantly, they then suggest, say, 21, to which the professor will say "does not fit the rule." Eventually, they will see that the rule is simply that "the next number in the sequence is higher than the previous one." What the students are eventually forced to do is to search for counterexamples to the rule with which they began. This game is a nice example of confirmation biases and how quickly we latch onto them; they are one of the biggest hobgoblins to effective scanning and sensemaking. Confirmation biases show how our minds look first to confirm the ideas or theories that we have with the common strategy for students being to look for confirming evidence of the idea that they held in their head. It isn't until the students realized that they had to try to disconfirm what they believe that they made real progress on discovering the actual rule, to try numbers that go against the logic-in-residence. There is an efficiency to our search, to collect as little as possible to justify what we believe. The opposite of this and the truest guide to effective sensemaking are to remain in the questioning state of mind and feeling comfortable doing so, rather than the reaching for the easy certainty of a preconceived conception. It's not that reaching a conception is bad-we would otherwise accomplish nothing - only that alone it is prone to major errors, not the sort of thing you want while forming new strategies.

(3) Sensemaking with mindfulness is about making distinctions or looking for contrasts or special cases. ${ }^{27}$ It is about the ability to avoid homogenization of the context, to avoid mashing-up of any rich detail into a monochrome viewpoint. Under the steamroller of organizational inertia and blinkered executive perspective, everything can become normalized and blended into "the way things are now." A famous and tragic example of

${ }^{27}$ Weick, K. E., K. M. Sutcliffe and D. Obstfeld. (1999). "Organizing for High Reliability: Processes of Collective Mindfulness.” In R. I. Sutton and B. M. Staw (Eds.), Research in Organizational Behavior, Vol. 21 (pp. 81-123). Elsevier Science/JAI Press. 
homogenization of rich detail is the Challenger Space Shuttle disaster and the subsequent analysis by Diane Vaughan. ${ }^{28}$ The Challenger Space Shuttle broke apart about a minute after its launch in January 1986, ending the lives of all seven crewmembers, an event that will be etched in the minds of millions as it was televised and the first catastrophic failure in the popular Space Shuttle program. The wide media coverage of the disaster and the investigative aftermath also meant that many adults today are strangely familiar with the obscure term "O-rings." A joint on one of the gigantic solid rocket boosters, which are really multiple cylinders joined together, upon which the Challenger was strapped had failed-the pressurized burning gas escaped from this joint and the boosters eventually began to tear-apart, leading to the break-up of the spacecraft. The speeds with which the Space Shuttle leaves the atmosphere means that it must have finely tuned aerodynamics to withstand the substantial air resistance and turbulence closer to earth, and so clearly anything that may disrupt that very short launch process is considered critical and taken very seriously. The reason the joint failed was that the rubber O-ring seals were not able to withstand the particularly cold temperatures that were present at launch. Investigation revealed, however, that these O-rings had a troubled past. It was known years before that serious erosion of O-ring seals was taking place, mostly to the first of the two O-ring seals but eventually also some erosion to the second O-ring. In fact, over half the missions in the few years before the disaster showed O-ring problems. The obvious question is how the documented problems with O-ring seals would be interpreted over time and whether they would be enough to curtail a mission? In other words, how do we make sense of these deviant observations? The answer was "normalization." O-ring problems over time, that is direct and repeated evidence that the O-rings were not working as they were supposed to, were confronted with the fact that the ships had successfully launched in the past, and that they were generally classified as redundant safety measures. As mission followed mission, the O-ring erosion and the risk of an O-ring failure were deemed acceptable. It's important to keep in mind that this is not a mathematical or algorithmic outcome-something that we can conclude on the basis of a calculation, which in this case signaled risk-it is a sociological outcome, that is an emerging, shared perception of what came to be considered normal risk

${ }^{28}$ Vaughan, D. (1996). The Challenger Launch Decision: Risky Technology, Culture, and Deviance at NASA. Chicago, University of Chicago Press; Vaughan, D. (1997). "The Trickle-Down Effect: Policy Decisions, Risky Work, and the Challenger Tragedy." California Management Review 39(2): 80-102. 
for this space program. And when things are normalized, we no longer see them as distinctions, nor do we take immediate corrective actions. As physicist Richard Feynman, the lead investigator in the Congressional Rogers Commission to look into the disaster's causes wrote in Appendix F of the report: "When playing Russian roulette the fact that the first shot got off safely is little comfort for the next." 29

\section{What the Financial Crisis of 2008 Teaches Us About Sensemaking}

The opposite of normalization is to be aware of discriminatory details, to track and stay attentive to the deviations from what is "normal" or commonly accepted interpretation. Some profound works of Science have been the result-not least perhaps two of the biggest of all time, the realization of Copernicus that the Earth is not the center of the solar system, and the painstaking work of Darwin on natural selection and evolution (the writing of which caused Darwin literal pain and illness, as he made sense of something so radically different to what his "normal" beliefs prescribed). Attention to discriminatory detail is also of big benefit to business people, and probably the biggest and most recent example occurred during the build-up to the global financial meltdown in 2008. It involved some impressive sensemaking by a small number of individuals.

For a long time, home property markets worked normally, i.e., people bought homes so that they and their families can live in them. They bought homes that they could afford, meaning homes where the interest and principal could be paid gradually from actual income streams over, say, a period of 10-30 years. Banks accepted only creditworthy buyers, verified creditworthiness, and required a standard percentage down payment. And if those mortgages were packaged into bonds (mortgage-backed securities), which by the way was not a new practice but one invented several decades before, lenders would be clued-into the quality and nature of those underlying assets. Regulators, or in this case the rating agencies such as Moody's, Standard and Poor's, and Fitch, would rate a security "AAA" only if it was a truly high quality, and therefore very safe, asset. This was "normal" practice for a long time.

\footnotetext{
${ }^{29}$ Feynman, Richard. (1986). Report of the Presidential Commission on the Space Shuttle Challenger Accident (In compliance with Executive Order 12546 of February 3, 1986). Appendix F. Washington, DC, July. Retrieved December 10, 2019. https://science.ksc.nasa.gov/shuttle/missions/51-1/docs/rogers-commission/table-of-contents.html.
} 
But something was definitely not normal in the build-up to the financial crisis of 2008, the core mechanisms of which we are by now well familiar and involved three main actors: buyers, lenders, and regulators. Buying a home had morphed into buying an "asset", an act of investment rather than just one of consumption. The value had less and less to do with the comfort of owning "my own castle" than the pleasure of making a killing "flipping" homes, or if you weren't actively flipping you were at least much more conscious of the price movement of what you now considered your asset and were open to making moves in the property market. I recall friends and relatives during those days admiring peers who were clever and entrepreneurial, who had enough ambition to enter the property market in this much more active and business-like way-and feeling like underachievers and dupes if you didn't. Eventually, and as we now know, this became an act of more or less pure investment and speculation for a growing segment of the population, and extended much further down the socioeconomic ladder than ever before, and, hence, stories emerged in the aftermath of the financial disaster of people who could barely make ends meet owning multiple properties.

This was made possible by the actions of some dodgy lenders and at two levels. On the frontline were the mortgage sellers. Incentivized to sell more mortgages, this is of course what they did, but with increasingly tricky and misleading terms. Lenders offered so-called teaser rates, temptingly low rates of interest for the first few years but that obfuscated the dramatic interest jumps thereafter. Eventually, mortgages were sold that were interest-only, but where those payments themselves could be rolled back into the principal-in other words, you paid nothing for the loan, you just had to worry about the timing of your exit from the property and how much profits to capture-or else cough up the value of the rapidly mounting principal. This ploy was designed for the home flipping market—clearly, the bet you took was that the value of the property would rise faster than the level of your debt. Finally, there were of course the major and trusted banks, the lenders who orchestrated this process, packaging these various mortgages into securities and selling them on, and on, to eventual lenders who, it turns out, knew very little about the underlying assets that they were buying. All they really knew, if even that, was that trusted rating agencies stamped the bundled assets as safe — and presumably they may not have known that some of these rating agencies may have been doing commercial work by these same banks.

Clearly, something very abnormal was happening in the home property market, but at the time no one detected the anomalies. The underlying assumptions- "property values over time march steadily upwards," 
"any corrections are temporary and never systematic, impacting the entire home market at once," and "a collapse in mortgaged-backed security values is no longer possible with modern finance"-were effectively scripture for the construction of that world. But, and as made (in)famous in Michael Lewis's engaging book The Big Short and the Adam McKay movie based upon it, a few people saw the signs early, including medical-doctor-turned-investor Michael Burry and equity-analyst-turned-financial-markets-skeptic Steve Eisman. While what they detected, and we briefly described above, were flagrant anomalies in the mortgage and related bonds market, we have to remember that at the time these things ran completely counter to the normal dogma about the property and mortgage-backed-securities market. Keep that fact in mind-many very clever, very well paid analysts had no clue what was happening in the mortgage and bond market. So what can we learn from Eisman and Burry about sensemaking? What did they do that allowed them to scan the same socioeconomic environment as millions of investors and, instead of going long on those markets, go not only short but with near certainty that a massive hurricane was bearing down on the global financial markets? First, they seemed to be naturally wary of "normal" things, of financial and mortgage dogma, the types of individuals who developed habits of mind that always left some reflective time and space for new conceptualizations of the things around them. Lewis captured this perfectly when he wrote that Burry's, "... job was to disagree loudly with popular sentiment." ${ }^{30}$ Eisman and Burry, then, felt personally empowered and free to try different conceptualizations of the world. This may have been partly because as financial analysts and investors, it is essentially their job to reconceptualize value, that is to figure out how much a company is actually worth, and this means having some level of doubt about normal or standard opinionafter all, it's hard to make money as an investor otherwise. But in Eisman and Burry's case, their degree of freedom with reconceptualizations seemed particularly strong.

Second, they had an incredible capacity to "stay in the question" for long periods of time. Eisman was particularly good at following a simple scripthe would stay in questioning mode a lot longer than people were comfortable with, as one of his close associates explained:

Steve's fun to take to any Wall Street meeting... Because he'll say 'explain that to me' thirty different times. Or 'could you explain that more, in English?'

${ }^{30}$ Lewis, M. (2011). The Big Short: Inside the Doomsday Machine. New York, W.W. Norton (p. 46). 
Because once you do that, there's a few things you learn. For a start, you figure out if they even know what they're talking about. And a lot of times they don't! ${ }^{31}$

This takes courage, not because you may be breaking social norms of politeness but because it is not easy to admit to yourself that you may not truly understand what is going on around you, even in a context where you believe you are an expert. It takes courage to test a dogma that you yourself probably hold. Burry's script was even more painstaking. He completely immersed himself in understanding this market and its instruments, and this included something other people were simply not doing: He actually read mortgage bonds, a brain-freezing and tedious task. But it was through this careful, questioning, investigative work that he first started to notice a major anomaly - the quality of the underlying assets was rapidly declining in the mid-2000s, specifically "interest-only" loans were a much bigger part of the mix, and these were more likely to be time bombs. Yet, lenders were more than willing to pile into the market, to give ever-increasing amounts of credit to increasingly risky buyers. In other words, Burry saw the seeds of the disaster, and just as important, he didn't try to explain it away in some fashion. For example, one could have reasoned as follows "well, yes, bonds were starting to accumulate more interest-only loans, but that risk could be diversified away by ensuring constant FICO (consumer creditworthiness measure) scores on the overall bond-discrepancy solved, the normal logic holds." Instead, as Lewis lays out in his book, Burry would dive deeper, untangling the FICO score itself, for example, and realizing that the variance of FICO scores in a bond, which could indicate risk, is not the same things as just their average. Finally, notice that this didn't come about because Eisman and Burry, although clearly clever and gifted, possessed some magical, sixth sense for investing, but because they had a process, and that process was fundamentally about digging, and testing, and examining. It is true that such sensemaking was put to use in shorting the housing market, and so allowing some to benefit from others misfortune and the corruption of a market, but the same sensemaking approach is required to fight the trap of normalization and to see (destructive) anomalies before they can do real harm.

Sensemaking is a field of study of some size by this point, and so about a lot more than what I have just outlined above. It also includes reflections about the self, that is your identity, and often in relation to the organization

${ }^{31}$ Ibid., p. 22. 
within which we exist and do our work. ${ }^{32}$ For our purposes, however, there are three main insights to gather from sensemaking in trying to build effective backstage scanning processes: (1) accept that an important part of your work is (re)conceptualization, (2) stay with the question and in the problem, and (3) look for anomalies and opportunities to test beliefs rather than quick paths to normalization.

Before we turn to the practical implications for scanning, however, it is useful to look more closely at the organizational context and recognize what we are up against, why mindful scanning and sensemaking may not come very naturally, and so why crafting and actively managing this process is important.

\section{When Scanning and Sensemaking Meet Dogma}

Dogma is principles or doctrines that are believed to be unquestionably true and backed by some authority. We normally associate dogma with autocratic regimes, where leaders are not to be questioned and believed to be the holders and protectors of true wisdom-not with contemporary business management. Mostly, we make fun of dogma today, as in the noir-comedy film "The Death of Stalin," which offers dark but hilarious portrayals of dogmatic moments. For example, in the film's eponymous scene, Stalin collapses in his office, only to be discovered hours later. Gradually, the members of the central committee arrive, but no one dares to call the doctor for fear of making some mistake on "protocol" in this situation, and certainly not before all members have arrived and a discussion and consensus decision can be reached. By the time they reach a decision in the safety of wider protocols, Stalin's condition clearly worsens, and he eventually dies. It's a light, comic example but one that well illustrates how dogma is often the enemy of free, creative thinking. Hence, it is also the most formidable enemy of scanning and sensemaking.

While a "Death of Stalin" situation is unlikely to happen in a truly entrepreneurial company, there are several ways in which organizations create dogmatic situations. Let's begin with the top of the organization. Top leaders will follow career paths that take many years to establish, and which will pull them into strategic topics and areas (financing, legal, etc.) and away from the frontline work and direct interface with the marketplace. This is

${ }^{32}$ Weick, K. E. (1995). Sensemaking in Organizations. Thousand Oaks, Sage. 
a natural career progression, and so it is also natural for top leaders to lose track of micro-developments in the marketplace and to rely instead on the principles that they believe to be fundamental to the company's success during their own march upward. This makes gaps likely between what they believe to be the best modus operandi on various dimensions and organizational routines and the needs and projections of the marketplace. We have already seen a classic example of how dogmatic thinking can prevent creative scanning and sensemaking-Polaroid's early lead in digital imaging, but thereafter its inability to craft novel business models because of a dogmatic belief by top leaders in the "razor-blade" revenue model. Louis Gerstner faced similar dogmatic forces at the top of IBM when he took over its leadership, discovering formal and internally focused dress codes, presentation formats that favored unidirectional transmissions over candid moments of open dialogue, and executive and political processes that were rituals worthy of Kremlinology studies and that prevented pathbreaking thinking. Fortunately, outsider Gerstner was able to break through the hidebound culture and thinking that had set IBM on a losing path to producing computer devices. For instance, he found areas where practices were at loggerheads with goals, such as IBM priding itself on its teamwork while compensating mostly on individual performance. Gerstner went on to break down those fiefdoms and compensate employees based on company performance. Also, by rewarding people for getting things done fast, he cut through what he called the company's "obsessive perfectionism" and its tendency for "studying things to death." He pushed IBM several steps further away from just hardware production to computing services and solutions (a vector IBM continues, and needs to continue, to this day). ${ }^{33}$

Next we have middle-to-senior management layers, including those who have substantial product, service, or business-level responsibilities, and who may suspect flaws in the dogma but are constrained by short-term metrics and needs. Here it's not necessarily a cognitive constraint that limits their ability to scan and make sense but simply a structural one. You know you have truly reached middle management ranks when every last available moment for free and creative thinking is absorbed by the immediate demands of quarterly earnings, administrative deadlines, and other, numerous, usually short term, KPI's and reporting duties. The result is that middle management ranks have very little precious bandwidth to do the sort of contemplative and futuristic work of scanning and sensemaking.

${ }^{33}$ Gerstner, L. V. (2002). Who Says Elephants Can't Dance? New York, HarperCollins. 
They often have few incentives as well. Take, for example, Havas, the global advertising company, who has been shifting its business model toward digital technologies and methods. Several years ago, they acquired a groundbreaking young advertising company by the name of Victor \& Spoils, groundbreaking because they relied on crowd-sourcing and a platform strategy to generate their proposals for clients, a massive savings in cost while expanding the potential pool of creatives. ${ }^{34}$ Unfortunately, this new model did not take off the way Havas hoped. For example, Havas didn't know how to incentivize existing, mostly local, business units to support the revenue growth of its small sibling. Presumably, worried about fulfilling its own P\&L requirements left little time to worry about this futuristic project.

Finally, let's consider organizational members that are nearer entry ranks, but include not only younger talent but also those who are immersed in specific technical tasks and projects and which may include middle-level managers. On the one hand, and on the back of having the most recent educational and development experiences, they may have the best purview on the gap between dogma and market and technological possibilities. This is something many companies are experiencing today in the pursuit of digitization of their business models, as they hire "digital natives" with data management and analysis skills. They may also be free of the KPI and reporting overload of their seniors. On the other hand, they are in the worst authority position to do much about whatever gap that they recognize. Moreover, the forces of socialization and a natural desire to fit in and get along mean that they may fear challenging the established dogma. This is basically what happened at Nokia, accounts of which a few of my colleagues have written. ${ }^{35}$ In short, engineers and project managers at Nokia recognized the true size of the challenge in front of them as they scanned and made sense of the software developments in mobile phone devices that were emerging out of Silicon Valley, a mecca for software development. They understood the advantages that a platform like iOS contained, and they recognized the weaknesses of the Symbian OS (Nokia's operation system). However, fear of speaking the truth to their seniors meant that the size of the real gap

\footnotetext{
${ }^{34}$ Lakhani, K. R. and M. L. Tushman. (2014). "Havas: Change Faster." Harvard Business School Case Study.

${ }^{35}$ Vuori, T. O. and Q. N. Huy. (2015). "Distributed Attention and Shared Emotions in the Innovation Process: How Nokia Lost the Smartphone Battle." Administrative Science Quarterly 61(1): 9-51; Doz, Y. L. and K. Wilson. (2018). Ringtone: Exploring the Rise and Fall of Nokia in Mobile Phones. Oxford, UK, Oxford University Press.
} 
between them and the software-based smartphone model was never properly revealed. For example:

Fearing the reactions of top managers, middle managers remained silent or provided optimistic, filtered information. One middle manager told us "the information did not flow upwards. Top management was directly lied to...I remember examples when you had a chart and the supervisor told you to move the data points to the right [to give a better impression]. Then your supervisor went to present it to the higher-level executives. There were situations where everybody knew things were going wrong, but we were thinking, "Why tell top managers about this? It won't make things any better." We discussed this kind of choice openly." ${ }^{\text {"W }}$

In sum, dogma is most likely to start at the top and be fiercely guarded from the top; middle and senior managers are most likely to be so immersed in the daily grind of meeting short-term targets that they have scarce time for scanning and sensemaking activities; and frontline ranks, while often in a good position to see gaps emerge, may lack the nerve to speak truth to power. Sadly, organizations are probably much better at preserving dogma than challenging it. Add to this the silos that tend to emerge in organizations, along with the vertical divisions, and that prevent the sharing of perspectives on the wider context and environment that is necessary for recognizing dogma, gaps and new opportunities. All things considered, it paints a grim image of modern organizations in their struggle to avoid disruption and capture new vectors. It also urges us to consider why it's all the more important that managers actively and successfully manage backstage processes to ensure the all-necessary scanning and sensemaking takes place.

\section{Putting Scanning and Sensemaking into Practice}

As already mentioned, your starting point would be to develop a search map (a list of various actors and institutions with which you need to interact or track) and make some judgment call on the frequency of interactions, their timing, and how they will be tracked. The ideas below are meant to deepen that basic process and hopefully increase its usefulness. They are certainly not meant to be exhaustive, and adaptations are always possible.

\footnotetext{
${ }^{36}$ Huy, Quy. (2015). “Who Killed Nokia? Nokia Did.” INSEAD Knowledge, September 22. Retrieved December 10, 2019. https://knowledge.insead.edu/strategy/who-killed-Nokia-Nokia-did-4268.
} 


\section{Develop Horizon Thinking}

Let's start with an obvious task. Scanning and sensemaking should be easier if a long-term viewpoint is developed, that is a sense of strategic intent and ambition that extends across the horizon rather than being fixed on some specific point in time, typically some 5-year window. This is important because the short term, and even the medium-term, is well defined with various metrics and targets, and so is likely to get all of the attention. It's important to raise people's heads from the daily grind so that they have a beacon for creative thought and sensemaking. Take for example the work of Pepsi Co.'s former CEO Indra Nooyi. Effectively from the start of her term, she has pushed Pepsi toward an unusual direction, what she called "Performance with Purpose." The horizon is defined by three elements: the planet (reducing the environmental impact of Pepsi Co.'s operations), the people (promoting human rights, diversity, and helping emerging regions and communities develop socially and economically), and the products. The work around the "the products" must have generated some internal eyebrow-raising, as Nooyi wanted the company to consider a horizon where they are producing healthier and more nutritious snacks and drinks-unusual because Pepsi made money by fulfilling our craving for fat and sugar. She summarized the predicament in an interview.

PepsiCo's business is three pieces. It has fun-for-you beverages and snacks: Pepsi, Mountain Dew, Lay's, Doritos, Fritos, Cheetos ... I could go on. All the 'tos. [Laughs] The second is what I would call better-for-you: Diet Pepsi, Baked Lay's, Baked Doritos. And then there's the good-for-you piece: Quaker Oats, Tropicana, Naked Juice. We are trying to take the fun-for-you portfolio and reduce the salt, sugar, and fat. I didn't create Pepsi Cola. I didn't create Doritos or Fritos or Cheetos. I'm trying to take the products and make them healthier. And guess what they tell me? "Don't be Mother Teresa. Your job is to sell soda and chips." So this is not being disingenuous. We are trying to take a historical eating and drinking habit that has been exported to the rest of the world and make [it] more permissible. ${ }^{37}$

The Performance with Purpose horizon was created in 2006. Yes, Pepsi Co. still produce plenty of sugary drinks today (although 7UP has about $1 / 3$

\footnotetext{
${ }^{37}$ Safian, R. (2017). "How PepsiCo CEO Indra Nooyi Is Steering the Company Toward a Purpose-Driven Future.” Fast Company. Fast Company Innovation Festival, January 9. Retrieved December 10, 2019. https://www.fastcompany.com/3066378/how-pepsico-ceo-indra-nooyi-is-steering-the-company-tow.
} 
less sugar), but they have managed to develop businesses like the Everyday Nutrition Business, which focuses on simple "positive" nutrition categories, such as whole grains, fruit and veg, proteins, dairy and hydration, and delivering them through various products.

This is clearly a long-term endeavor, and the jury is still out how far Performance with Purpose will go, but what Nooyi managed to see in 2006 was a disruptive force that seems to be building with time: People are demanding more nutrition from food companies. The relationship between people and food is mediated by massive companies, with substantial marketing budgets, and so with the power to direct consumers, particularly kids, toward "fun" but not nutritious products. This is a disruptive force, because consumers can rapidly turn against brands and companies that they feel may be doing more harm than good. By taking a long-term view-reaching out to the horizon - she has helped guide and encourage the scanning and sensemaking work of various people within Pepsi, from people in Pepsi labs to marketers. The general point is that developing a horizon, that is a long-term view, without necessarily "pinpointing" or over-defining it, should help raise people's heads and benefit the scanning and sensemaking work within the company.

Another leader that has been recognized for her horizon thinking is Ginni Rometty, who became the first woman to run IBM, taking the helm from CEO Sam Palmisano in 2012 and stepping down in early 2020. Rometty generously credits both Palmisano and his former CEO Lou Gerstner, with teaching her the value of reinvention. "No matter what," she says, "you've always got to focus on reinvention, right? Never love something so much that you can't let go of it. And you have to reinvent." 38 And, with that horizon view in mind, Rometty has been actively trying to reinvent IBM during her tenure, pushing the firm further into services. Forbes recently named her one of its "Power Women" for "heralding IBM's transition into a data company, pushing its cloud and analytics products to counteract a decline in the demand for legacy software products." Under Rometty's leadership fully half of the company's 2017 revenue came from those emerging cloud and analytic products, and Rometty put the strategy front and center by purchasing open source cloud software business Red Hat in 2018 for $\$ 34$ billion, which put the company in a better position to compete with Microsoft and Amazon in cloud

\footnotetext{
${ }^{38}$ Huey, John. (2012). “Transcript: IBM's Ginni Rometty on Leadership.” Fortune, October 2. Retrieved August 17, 2019. https://fortune.com/2012/10/02/transcript-IBMs-ginni-rometty-onleadership/.
} 
computing. ${ }^{39}$ Once again, it is hard to predict if these moves will have been fast enough to push IBM nearer to the front of the cloud pack, and the proverbial jury is still out, but Rometty has at least attempted to create some horizon thinking.

\section{Build Scanning and Sensemaking Activities i nto the Everyday}

Do enough people have time allocated in their workdays to scan and make sense? Don't underestimate the pull of short-term goals and projects, since people tend to give the most attention to those things that are immediate and measured action items (despite our moments of delightful procrastination). The most creative companies and today's tech disrupters budget time for such creative scanning work into every employee's schedule and that time, importantly, includes permission to fail. For example, $\mathbf{3} \mathbf{M}$ is probably the poster child for innovative companies and includes some creative and powerful structures and processes, such as: managers (called "inventors") can seek seed funding from business unit leaders, an internal network exists that matches entrepreneurial ventures to talent, creative types have a dual career track that allows them to keep a hand in innovation even as they advance in management. ${ }^{40}$ But a cornerstone of this approach to innovation is time. $3 \mathrm{M}$ has a $15 \%$ rule that states employees are expected to spend $15 \%$ of their time on whatever they choose, but generally looking at weird and wonderful new opportunities or issues, and so when employees from the disease-prevention unit explored Bluetooth technologies, they built these technologies into electronic stethoscopes, allowing doctors to transmit data in real time to servers for deeper and quick analysis. Without the $15 \%$ rule and a tolerance for human failure, presumably, such heralded $3 \mathrm{M}$ inventions as reflective traffic signs, Scotchgard fabric protector, Post-Its and Scotch tape would not have their prime place in our lives and drive billions in sales for $3 \mathrm{M} .{ }^{41}$

We need to be careful, however, about reducing this to simply time management. Google also has its own skunkworks policy for individually

\footnotetext{
${ }^{39}$ Kuehner-Hebert, Katie. (2018). "How CEO Ginni Rometty Is Reshaping IBM." Chief Executive, March 26. Retrieved September 22, 2019. https://chiefexecutive.net/ceo-ginni-romettyreshaping-IBM/.

${ }^{40}$ Govindarajan, V. and S. Srinivas. (2013). "Innovation Mindset in Action: 3M Corporation." Harvard Business Review, August 6.

${ }^{41}$ Weis, Dusty. (2018). "Giving Employees Permission to Fail is a Formula for Innovation at 3M." Association of Equipment Manufacturers, June 21. Retrieved August 20, 2019. https://www.aem.org/ news/giving-employees-permission-to-fail-is-a-formula-for-innovation-at-3M/.
} 
directed projects called the $20 \%$ rule, and it has been credited with such inventions as Google News, Gmail, and AdSense. However, there is dissenting opinion about how well, or how clearly, this works within Google. ${ }^{42}$ First, it seems that employees, even at Google (!), are constrained by the near-term goals of existing products and projects, and to such an extent that the "20\% rule" is more like a $5 \%$ rule, or a $10 \%$ hope. The reality is that as long as you do the formal task for which you have been hired, you can spend the extra time on special projects. Marissa Meyer, Google's 20th employee who went on to become CEO of Yahoo!, said, when asked why she didn't institute Google's 20\% policy at Yahoo!, "I've got to tell you the dirty little secret of Google's 20\% time. It's really 120\%." Meyer went on to explain that the $20 \%$ was usually added on to time spent doing required tasks. ${ }^{43}$ Of course, Google hires some very capable people, and so they are more likely to finish their normal work in less than $100 \%$ of their time. Writers on innovation also say that big new ideas often occur when working in concert with others, on daily jobs, and not in some lone corridor where creativity is supposed to flourish. What's more important, they say, is ensuring that employees who do happen to come up with a novel idea-whether on their own time or during the middle of an Agile stand-up meeting-have the backing and encouragement to pursue it. It's clear there needs to be active managerial oversight on whether that rule is being followed or used. Google is fortunate in that it has by now a strong and natural proclivity for disruptive thinking and invention, a disruptive culture embedded in the normal, but many companies don't have this. In those cases, offering both the time for active scanning and sensemaking but then also watching and managing that process by encouraging failing paths as much as promising ones, is an important aspect of backstage leadership.

\section{Decentralize Your Scanning Activities}

The single most vital ingredient for scanning and sensemaking would have to be capturing a diversity of viewpoints, and in the context of a business organization this means capturing insights up and down the corporate

\footnotetext{
${ }^{42}$ D’Onfro, Jillian. (2015). “The Truth About Google’s Famous '20\% Time’ Policy.” Business Insider (France), April 17. Retrieved December 10, 2019. http://www.businessinsider.fr/us/google-20percent-time-policy-2015-4.

${ }^{43}$ Hill, George. (2019). "The Myth of Google's 20\% Time." Chief Innovation Officer (Innovation Enterprise Channels). Retrieved August 20, 2019. https://channels.theinnovationenterprise.com/ articles/the-myth-of-google-s-20-time.
} 
hierarchy as well as outside, and triangulating data in order to develop intuition. It is a process that needs to be done proactively. Consider the following study of how the scanning process leads, or doesn't, to new innovations. ${ }^{44}$ The target population were executives from 22 metal-casting firms in the United States-not your usual Silicon Valley disruption behemoths, but therefore a great place to look at how well scanning activities can nudge some old and highly institutionalized practices. The study looked deeply at the scanning and knowledge use of these organizations, over several months, and also at the subsequent innovation outcomes. One of the differences the study established was between adaptive innovation outcomes ("tweaking" a standard technology) and more disruptive outcomes (more "radical" innovation outcomes). What were the drivers of the more disruptive innovation outcomes? First, more disruptive innovations began with executives generally emphasizing broader, technological understanding and not simply operational efficiency, that is they sought an "outside-in" viewpoint that struck at the technological foundations of the firm, rather than one that focuses on reexamining and altering the way things are done internally already. To be sure, those who innovated incrementally did exhibit intense scanning, but it was not comprehensive and external "outside-of-the-box" thinking or particularly proactive. Also, executives in the incremental innovation camp tended to believe in the superiority of their own skills and knowledge, rather than being more proactive among peer organizations, suppliers, and industry workshops in seeing what is new. In other words, there is a good deal of humility in scanning. Another telling aspect of the study is that firms in the sample that displayed little uncommon knowledge use and innovation-tending to focus on maintaining responsiveness to current customers and infrequent and passive scanningalso believed that worker's knowledge is limited. This seems like an excellent recipe for inertia: Focus only on what your current customers want and ignore letters from the frontlines.

Second, and particularly relevant here, more disruptive innovations came from companies where inputs from lower-echelons were taken more seriously. In those more radically innovative companies, there was a strong belief that workers are capable and knowledgeable. This helped foster a working environment where initiative and experimentation were more widespread, the sort of engagement that can help move mere whims into actionable ideas

\footnotetext{
${ }^{44} \mathrm{Nag}$, R. and D. A. Gioia. (2012). "From Common to Uncommon Knowledge: Foundations of Firm-Specific Use of Knowledge as a Resource." Academy of Management Journal 55(2): 421-457.
} 
and eventually projects. The successful innovators in the study watched out for and did not put on the blinders of organizational dogma, the belief that hierarchy is the best predictor of scanning and sensemaking capability, that those lower in the organization should focus on execution and leave the creative scanning work to "those who know what they are doing." In sum, the study strongly suggests that sort of thinking is likely to be the enemy of capturing a diversity of viewpoints so crucial to decentralized scanning.

All in all, this study supports well the idea that diversity of viewpointsup and down the hierarchy and status ladder-should help a firm discover more disruptive or innovative pathways. Yes, some firms may prefer a highly centralized scanning process. Take, for example, Ikea, whose massive size and scale means that changes must be gradual and well planned, with a long time horizon - after all, if Ikea decides to shift even one factor, say from pine to birch in its wood selection for coffee tables or bookshelves, this may require enormous investments in birch forests, logging contracts, etc. The consequence of which may mean that scanning itself may tend to be more centralized, and, according to a former Ikea manager, this is why local store managers at Ikea are focused on moving merchandise out the door, not worrying about scanning for fashion. But most companies are not the size and scale of Ikea and should consider a decentralized backstage scanning process. Having scanning occur through a single, typically senior, committee, or possibly single individual, is likely to leave a lot of valuable insight locked away in some corner of the organization. Thus, create backstage scanning processes that are decentralized, that look widely within the company for ideas and viewpoints. ${ }^{45}$

\section{Bring Outsiders In}

It's not only important to emphasize the value of looking to outsiders, people who are not core players in your industry, but also to find ways to bring their outsider viewpoints inside. Sometimes even many insiders do not see the external threats and opportunities. For example, another of the early detectors of opportunity within the 2008 subprime mortgage chaos was Greg Lippmann, a trader with Deutsche Bank who had been placing bets against this market despite his superiors becoming very nervous with the

${ }^{45}$ Teece, D. J. (2012). "Dynamic Capabilities: Routines Versus Entrepreneurial Action.” Journal of Management Studies 49(8): 1395-1401. 
gamble. What he could not understand was why the market continued to roll on and up despite the quality of the loans becoming progressively worse. What he discovered, however, was that the closer you were to this marketliterally the people who ran the funds that traded on mortgage bonds-the less likely you were to see that anything was wrong. It seemed that insiders reached a point beyond "irrational exuberance," a sort of religious belief in the underlying logic of their business model. Eventually, Lippmann had to seek the sanity and help of relative outsiders, for example, stock rather than bond investors with enough exposure to falling home prices that they could be convinced of the need to hedge against the market's collapse. This eventually led him to Steve Eisman and his team, a team of "outsiders" who shared the same dim view of the mortgage-backed securities market. ${ }^{46}$

The view of considering users that are not yours, that are so-called noncustomers, was popularized by my colleagues Kim and Mauborgne in their work on Blue Ocean Strategies. ${ }^{47}$ They point to three tiers of noncustomers, tiers that gradually move away from your core users group:

*soon-to-be noncustomers - those who interact with your products or industry only until they find something else, for example, busy professionals who would go to sit-down restaurants for lunch only until fast-but-healthy food options appeared on the scene in city centers; enter British chain Pret-a-Manger with restaurant-quality sandwiches prepared fresh every day and offered at faster speed than sit-down fast-casual chains and fast-food restaurants.

* refusing noncustomers-people who refuse to use or cannot afford the current industry offerings, such as the expensive billboards that get questionable traction for advertisers anyway. JCDecaux, a French vendor of outdoor ad space, gained the eyeballs of refusing noncustomers for billboards when it developed outdoor advertising on what it called "street furniture," bus stops and benches in downtown locations.

* unexplored noncustomers-those customers or needs that seem very distant from your marketplace, such as person-to-person or small merchant transactions in the credit card world, a big market that credit card companies have ignored, and which opened an opportunity for a company like Square. Another example is tooth whitening services. Oral care companies that offer toothbrushes, toothpaste, and dental floss always considered tooth whitening the purview of dentists until they explored noncustomers

\footnotetext{
${ }^{46}$ Lewis, M. (2011). The Big Short: Inside the Doomsday Machine. New York, W.W. Norton (p. 90).

${ }^{47}$ Kim, W. C. and R. A. Mauborgne. (2005). Blue Ocean Strategy. Boston, MA, HBS Press.
} 
and realized they could get in on this lucrative market with products like tooth-whitening strips. ${ }^{48}$

Unfortunately, many attempts to engage external contributors fail-and despite growing access to some powerful online idea solicitation tools, such as the "Fan Machine" of advertising firm Victors \& Spoils, which leverages Facebook Fans of brands to solicit new product/service ideas. So while research has shown that scanning and suggestions from outsiders are useful if not critical to innovation of various sorts, ${ }^{49}$ companies have struggled to make this work. We have to wonder if new digital tools would make this easier and more effective. After all, there are only so many people-hours that you have, for networking, visiting, exploring, with outside bodies, and so turning to digital tools would make sense. A few scholars have looked into this problem recently, including Professor Henning Piezunka: what can leaders and organizations do to ensure outsiders contribute views and suggestions, and in particular with digital tools? ${ }^{50}$ Piezunka's research taps the experiences of over 23,000 firms and their use of a special software that embeds suggestion boxes onto the firm's website. It captures not only successful companies and campaigns but also the unsuccessful ones, so that a proper comparison can be made. The main outcome that they were observing is the volume of suggestions that companies can solicit. Keep in mind that getting outsiders to offer any suggestions for product/service development is difficult. In fact they found that responses in general were very rare; the median firm only received about one response per month, and you have to go to the top $1 \%$ of companies to see roughly one response per day. So what separated the successful from unsuccessful companies? Proactive engagement by insiders is useful. Firms that seeded posts and suggestions from insiders, particularly in the early stages, were much more likely to see outsiders join in. Outsiders are more likely to take your scanning quest seriously if they see that you yourselves are engaged. Also, responding actively to contributors is important. More suggestions emerge as firms were seen to engage with contributors and especially newcomers to the scene. Again, outsiders want to see that their time is being taken seriously. In sum, outsiders

\footnotetext{
${ }^{48} \mathrm{Kim}$, W. Chan and Renee A. Mauborgne. (2015). "3 Types of Noncustomers and How to Sell to Them." Hubspot.com, March 11. Retrieved August 21, 2019. https://blog.hubspot.com/sales/ types-of-noncustomers-and-how-to-sell-them.

${ }^{49}$ Danneels, E. (2008). "Organizational Antecedents of Second-Order Competences." Strategic Management Journal 29(5).

${ }^{50}$ Dahlander, Linus and Henning Piezunka. (2014). "Open to Suggestions: How Organizations Elicit Suggestions Through Proactive and Reactive Attention." Research Policy 43(5): 812-827.
} 
should be a key target in scanning, and this will of course require you to map, network and build relationships and taskforces into various corners of your ecosystem. Digital tools, however, can also be effective, but they require some sensible backstage processes, such as active seeding and attention from insiders, preferably early in the process.

\section{Aggregate, Align, and Take Deep Dives}

So far, we have seen that (1) scanning can be helped by lifting people's gazes and building horizon thinking, (2) scanning not only requires time and resources but active oversight, (3) capturing a decentralized, diversity of viewpoints is valuable, and (4) tapping enough "foreigners" in the scanning process is key-especially noncustomers. However, all of this work can amount to very little if you don't have an aggregation process, a way to allow the sensemaking to properly take place. Scanning, especially when decentralized, needs to be aggregated, and another way to think about sensemaking. It needs to be linked-up to the strategic decision-making process and to create a channel for execution. Consider the experiences of a former student of mine who is an executive at a multinational banking and financial services company, a bank that is very mindful of fintech, digital technologies in banking such as automated, algorithm-driven robo-advisors like Betterment and Wealthfront that can provide clients with investment advice and portfolio options, and the threats that they pose to conventional banking. He is engaged in the sort of scanning activities that make good sense-for example, having dedicated fintech teams explore technological possibilities not just from other banks but from technology companies (i.e., outsiders). But that is not enough. These scanning moments are of little use if they are not somehow aggregated, linked back to the core strategic planning process, as he explains:

The scanning is done in a way that we have [at] the level of the CEO office, and on the level of the top executive committee, we have kind of a standard strategy review process. So, we always go through our strategy, what has changed, what has worked, what do we have to adopt, and on the parallel side we're following like a scorecard where we have all the trends...we really try to follow the trends and we more or less put them into an order, saying, 'Okay, how big is the potential that this actually comes through... ${ }^{51}$

${ }^{51}$ Galunic, C. (2017). "Digital Journeys: 10 Checkpoints in Building a Digital-Ready Company." INSEAD Case 11/2017-6349. 
By linking the scanning process back to a decision-making body, and one in this instance that can obviously impact strategy and make things happen, the scanning process is more likely to come full circle and have impact.

This sort of aggregation needs to be analytical, leaving enough time for creative brainstorming and interpretation, to revisit and update prior assumptions about products and services and what's on the horizon. This is what the global design company IDEO calls a "deep dive," a full immersion into the problem at hand.

Another former student of mine seems to understand this well. Goran Westerberg is CEO of Swedish-based Rusta, a growing home and leisure products company catering to the Scandinavian market. Take two examples, the first involving something as mundane as a tea kettle. First, Rusta's range team closely follow and aggregate information and viewpoints from various sources, including social media trends and inputs, product fairs across the world, discussions with producers and inventors, and close looks at competitors like giant Costco. What they found when it came to the boring water kettle is that this item is particularly price sensitive. What they also discovered is that there was room in the marketplace for even greater value in something so mundane, that the prevailing assumption about the low-end price point may not be correct and needs to be updated:

It's not like it's a new invention, it's been around for donkey's years, and there is a fair amount of competition for this product. But that is an item a lot of people want to buy, and we have seen that volumes go up quickly, very very quickly, when we reduce the price. So we worked with various producers and designers around the world and we told them that if you succeed in reaching a certain price point, we will give you huge volumes...so it was a good looking stainless steel kettle, but simple, we reduced the number of parts, we looked at thickness, every component... a similar [most] inexpensive product sold for about $10-15 €$, we managed to come-up with a product that looks great and sells for about $5 €$ ! And we make a profit... The first day we sold 10,000 kettles in one day!

Rusta's general strategy is a volume strategy, to look for items that will move quickly and in great volumes, so they are not discovering a new strategy per se, but their scanning and aggregation process helps them to discover value in places that others may have stopped looking, such as in a simplebut high usage-kitchen instrument. "What we try to do is stay close to the common person... and it's fun!" he went on to say. 
Westerberg gave another example, one with a body mist, a more pop-culture oriented product and one associated with a large popular brand, Victoria's Secret. First of all, what his team had noticed was that, until a few years ago, there were no stores in the Nordic region for people to get their hands on Victoria's Secret products, even though there was growing consciousness of and yearning for the brand in the Nordics. Hence, this Victoria's Secret body mist became, essentially, a luxury item in Sweden, even though the brand is generally a mass market brand in the United States. This helped Rusta recognize an opportunity:

So, on the high street, the hairdresser, for example, would take some of these samples and sell them for ridiculous prices, and in the US they would be a fraction of that. We identified that. How did we do that? We looked at our own kids, I regularly asked my own kids, we looked at social media, etc. And then we started to scan the market to see if there were any stock lots available. There were not. We continued to search and search and search, and in the end we found a 'middleman' that connected us to production in the US. We managed to get our hands on over 700,000 bottles. We put it on our front page- the going rate in Sweden was about 299 kroner, and we put it out there at 99 kroner. And we had a healthy margin. We sold out in two weeks! We crushed the market.

Westerberg went on to reveal a more important part of their sensemaking opportunity and decision logic.

The [important] thing that this does for our brand is, \#1, we are bringing in tons of young people, who will talk about this, who will spread it on social media, who will say 'what, you got that for what price?' And that was exactly what happened! It just exploded. And it really underlined our low price position... Our value proposition for customers is lower price, but two more things: one, a joyful hunt for bargains!...two, we look for arbitrage opportunities on what are perceived as luxury items [but can be delivered for a lot less].

For Westerburg, this was less about simply moving a product in volumes, and with a healthy margin; it was more about the branding opportunity and especially among tomorrow's consumers. For him and his team, they saw this as a great vehicle to underline the purpose of the Rusta brand-low cost and relevant-aligning the scanning work with the company strategy. That word "relevance" is key to Westerberg's alignment of sensemaking with strategy. The main question he asks himself and his team is, as he puts it, "Do we have relevant offers-if we don't have relevant offers for our customers and fulfill our customer promise, then we are nothing. It doesn't matter what 
channel we use, whether physical or online, if we don't have a relevant offer, nothing else matters." Westerburg went on to quote something to that effect from a Rusta founder. In other words, it's not only that Westerburg did the work, but also that he represented the implicit logic behind the brand, and elements of the corporate culture, to make sure that ideas that were being aggregated-bubbling up through the process-met those fundamental criteria. Yes, the elements of the logic may have to be revisited from time to time (as Polaroid failed to do), but you are more likely to capture their lack of fit if you have an open, honest, and ongoing debate about the nature of the threats and opportunities at hand and remain closely in touch with the data and the phenomena around you. Westerburg's role essentially boils down to facilitating that process and guarding its honesty and integrity.

Finally, keep in mind that there is no magical "insider's" view when it comes to scanning or forecasting of any sort, no secret code that you are trying to break, but that the process is about gradually refining your intuition, over thousands of data points, looking for causality and implications for your strategy and business. Every sweep of scanning and the sensemaking activities that follow are opportunities to update, to improve, your interpretation about what is actually going on in the market. What is real? What are duds? What should we continue to follow? What can we scrap as a mere fad? What you are trying to do is construct a process where your guesses-your approximations-get a constant workout, are constantly challenged and refined until the moment where there is enough confidence that you are seeing the emering reality appear, the true signal and not mere noise. (for more on forecasting and statistics, see Nate Silver's (2012) “The Signal and the Noise”, Penguin.)

\section{References}

Arnold, Carrie. (2014). "Spiders Listen to Their Webs." National Geographic, June 5. Retrieved December 10, 2019. https://news.nationalgeographic.com/ news/2014/06/140605-spiders-silk-webs-pluck-string-vibrations/\#close.

Baer, Drake. (2014). "The Making of Tesla: Invention, Betrayal, and the Birth of the Roadster." Business Insider, November 11. Retrieved December 10, 2019. https://www.businessinsider.fr/us/tesla-the-origin-story-2014-10.

Brewis, Kathy. (2017). "Harnessing the Winds of Change: BlaBlaCar." London Business School, July 17. Retrieved December 10, 2019. https://www.london.edu/ lbsr/iie-harnessing-the-winds-of-change-BlaBlaCar.

Cattani, Gino. (2008). "Leveraging In-House R\&D Competencies for a New Market: How Corning Pioneered Fibre Optics." International Journal Technology Management 44(1/2): 28-52. 
CNBC. (2019). "Meet the 2019 Disruptor 50 Companies." May 15. Retrieved August 19, 2019. https:/www.cnbc.com/2019/05/15/meet-the-2019-cnbc-disruptor-50-companies.html.

Crawford, Susan. (2019). "How Corning Makes Super-Pure Glass for Fiber-Optic Cable.” Wired, January 8. Retrieved August 21, 2019. https://www.wired.com/ story/corning-pure-glass-fiber-optic-cable/.

Dahlander, Linus and Henning Piezunka. (2014). "Open to Suggestions: How Organizations Elicit Suggestions Through Proactive and Reactive Attention." Research Policy 43(5): 812-827.

Danneels, Erwin. (2008). "Organizational Antecedents of Second-Order Competences." Strategic Management Journal 29(5): 519-543.

Dans, Enrique. (2018). "Tesla, The Model 3...And the Market." Forbes, August 4. Retrieved December 10, 2019. https://www.forbes.com/sites/ enriquedans/2018/08/04/Tesla-the-model-3-and-the-market/\#1cc6906577ed.

D’Onfro, Jillian. (2015). "The Truth About Google's Famous '20\% Time' Policy." Business Insider (France), April 17. Retrieved December 10, 2019. http://www. businessinsider.fr/us/google-20-percent-time-policy-2015-4.

Doz, Yves L. and Keeley Wilson. (2018). Ringtone: Exploring the Rise and Fall of Nokia in Mobile Phones. Oxford, UK, Oxford University Press.

Eggers, J. P. and Sarah Kaplan. (2009). "Cognition and Renewal: Comparing CEO and Organizational Effects on Incumbent Adaptation to Technical Change." Organization Science 20(2): 461-477.

Eisenhardt, Kathleen M. and Jeffrey A. Martin. (2000). "Dynamic Capabilities: What Are They?" Strategic Management Journal 21: 1105-1121.

Feynman, Richard. (1986). Report of the Presidential Commission on the Space Shuttle Challenger Accident (In compliance with Executive Order 12546 of February 3, 1986). Appendix F. Washington, DC, July. Retrieved December 10, 2019. https://science.ksc.nasa.gov/shuttle/missions/51-1/docs/rogers-commission/table-of-contents.html.

Galunic, Charles. (2017). "Digital Journeys: 10 Checkpoints in Building a DigitalReady Company.” INSEAD Case 11/2017-6349.

Galunic, Charlies and Kathleen M. Eisenhardt. (2001). "Architectural Innovation and Modular Corporate Forms." Academy of Management Journal 44(6): 1229-1249.

Galunic, Charles and Simon Rodan. (1998). "Resource Recombinations in the Firm: Knowledge Structures and the Potential for Schumpeterian Innovation." Strategic Management Journal 19(12): 1193-1201.

Gannes, Liz. (2013). "Europe's BlaBlaCar Has Created the Purest Version of the Sharing Economy So Far-And It's Working-All Things D." The Wall Street Journal, December 2. Retrieved December 10, 2019. https://techcrunch. com/2018/09/24/BlaBlaCar-is-on-the-path-to-profitability/.

Gerstner, Louis V. (2002). Who Says Elephants Can't Dance?: Inside IBM's Historic Turnaround. New York, HarperCollins. 
Goldenberg, Jacob and Rom Y. Schrift. (2018). "Go Forth and Multiply: Unlocking Successful Innovation.” Columbia CaseWorks Case: 190501.

Govindarajan, Vijay and Srikanth Srinivas. (2013). "Innovation Mindset in Action: 3M Corporation." Harvard Business Review, August 6.

Hill, George. (2019). "The Myth of Google's 20\% Time.” Chief Innovation Officer (Innovation Enterprise Channels). Retrieved August 20, 2019. https://channels. theinnovationenterprise.com/articles/the-myth-of-google-s-20-time.

Huey, John. (2012). “Transcript: IBM's Ginni Rometty on Leadership.” Fortune, October 2. Retrieved August 17, 2019. https://fortune.com/2012/10/02/ transcript-IBMs-ginni-rometty-on-leadership/.

Huy, Quy. (2015). "Who Killed Nokia? Nokia Did." INSEAD Knowledge, September 22. Retrieved December 10, 2019. https://knowledge.insead.edu/ strategy/who-killed-Nokia-Nokia-did-4268 (p. 515).

Kim, W. Chan and Renee A. Mauborgne. (2005). Blue Ocean Strategy. Boston, MA, HBS Press.

Kim, W. Chan and Renee A. Mauborgne. (2015). "3 Types of Noncustomers and How to Sell to Them.” Hubspot.com, March 11. Retrieved August 21, 2019. https://blog.hubspot.com/sales/types-of-noncustomers-and-how-to-sell-them.

Kruse, Kevin. (2018). "Netflix Culture Deck Co-Creator Says Leaders Need to Explain Context." Forbes, February 19. Retrieved August 21, 2019. https://www. forbes.com/sites/kevinkruse/2018/02/19/Netflix-culture-deck-co-creator-saysleaders-need-to-explain-context/\#bb3528b590c2.

Kuehner-Hebert, Katie. (2018). "How CEO Ginni Rometty Is Reshaping IBM." Chief Executive, March 26. Retrieved September 22, 2019. https://chiefexecutive.net/ceo-ginni-rometty-reshaping-IBM/.

Lakhani, Karim R. and Michael L. Tushman. (2014). "Havas: Change Faster." Harvard Business School Case Study Multimedia/Video Case 615-702, September.

Lewis, Michael. (2011). The Big Short: Inside the Doomsday Machine. New York, W.W. Norton.

Nag, Rajiv and Dennis A. Gioia. (2012). "From Common to Uncommon Knowledge: Foundations of Firm-Specific Use of Knowledge as a Resource." Academy of Management Journal 55(2): 421-457.

Nocera, Joe. (2015). "Can Netflix Survive in the New World It Created?" The New York Times Magazine. New York Times (New York), June 15. Retrieved December 10, 2019. https://www.nytimes.com/2016/06/19/magazine/can-netflix-survivein-the-new-world-it-created.html.

Rumelt, Richard. (2011a). Good Strategy Bad Strategy: The Difference and Why It Matters. New York, Crown Business.

Rumelt, Richard. (2011b). "The Perils of Bad Strategy." McKinsey Quarterly 1(3): 1-10, June. Retrieved August 19, 2019. https:/www.mckinsey. com/business-functions/strategy-and-corporate-finance/our-insights/ the-perils-of-bad-strategy. 
Safian, Robert. (2017). "How PepsiCo CEO Indra Nooyi Is Steering the Company Toward a Purpose-Driven Future." Fast Company. Fast Company Innovation Festival, January 9. Retrieved December 10, 2019. https://www.fastcompany. com/3066378/how-pepsico-ceo-indra-nooyi-is-steering-the-company-tow.

Teece, David, Gary Pisano and Amy Shuen. (1997). "Dynamic Capabilities and Strategic Management.” Strategic Management Journal 18(7): 509-533.

Teece, David, Margaret Peteraf and Sohvi Leih. (2016). "Dynamic Capabilities and Organizational Agility: Risk, Uncertainty, and Strategy in the Innovation Economy." California Management Review 58(4): 13-35.

Teece, David J. (2007). "Explicating Dynamic Capabilities: The Nature and Microfoundations of (Sustainable) Enterprise Performance." Strategic Management Journal 28(13): 1319-1350.

Teece, David J. (2012). "Dynamic Capabilities: Routines Versus Entrepreneurial Action." Journal of Management Studies 49(8): 1395-1401.

Tripsas, Mary and Giovanni Gavetti. (2000). "Capabilities, Cognition, and Inertia: Evidence from Digital Imaging.” Strategic Management Journal 21(10/11): 1147.

Ulaga, Wolfgang, Joerg Niessing and Nancy Brandwein. (2019). "WeWorkService Excellence Through Business Model Innovation: Creating Outstanding Customer Experiences by Leveraging Data, Analytics and Digital Technologies." INSEAD Case: \#TK.

Vaughan, Diane. (1996). The Challenger Launch Decision: Risky Technology, Culture, and Deviance at NASA. Chicago, University of Chicago Press.

Vaughan, Diane. (1997). "The Trickle-Down Effect: Policy Decisions, Risky Work, and the Challenger Tragedy." California Management Review 39(2): 80-102.

Vuori, Timo O. and Quy N. Huy. (2015). "Distributed Attention and Shared Emotions in the Innovation Process: How Nokia Lost the Smartphone Battle." Administrative Science Quarterly 61(1): 9-51.

Weick, Karl E. (1995). Sensemaking in Organizations, Vol. 3. Thousand Oaks, Sage.

Weick, Karl E. and Kathleen M. Sutcliffe. (2006). "Mindfulness and the Quality of Organizational Attention." Organization Science 17(4): 514-524.

Weick, Karl E., Kathleen M. Sutcliffe and David Obstfeld. (1999). "Organizing for High Reliability: Processes of Collective Mindfulness." In R. I. Sutton and B. M. Staw (Eds.), Research in Organizational Behavior, Vol. 21 (pp. 81-123). Elsevier Science/JAI Press.

Weis, Dusty. (2018). "Giving Employees Permission to Fail is a Formula for Innovation at 3M." Association of Equipment Manufacturers, June 21. Retrieved August 20, 2019. https://www.aem.org/news/giving-employees-permissionto-fail-is-a-formula-for-innovation-at-3M/. 